\title{
The impact of diabetes mellitus on survival after myocardial infarction: can it be modified by drug treatment?
}

\section{Results of a population-based myocardial infarction register follow-up study}

\author{
H.Löwel ${ }^{1}$, W.Koenig ${ }^{2}$, S. Engel ${ }^{3}$, A.Hörmann ${ }^{4}$, and U.Keil ${ }^{5}$ \\ ${ }^{1}$ GSF-Institute of Epidemiology, Neuherberg, Germany \\ ${ }^{2}$ Department of Internal Medicine II-Cardiology, University of Ulm, Ulm, Germany \\ ${ }^{3}$ Central Hospital of Augsburg, Augsburg, Germany \\ ${ }^{4}$ GSF-Medis-Institute, Neuherberg, Germany \\ ${ }^{5}$ Institute of Epidemiology and Social Medicine, University of Münster, Münster, Germany
}

\section{Abstract}

Aims/hypothesis. Mortality of diabetic patients after myocardial infarction remains high despite recent improvement in their management. This study population-based evaluates the impact of cardiovascular drug therapy on mortality within 28 days and during 5-year follow-up in diabetic compared with non-diabetic patients.

Methods. Using the MONICA Augsburg register from 1985 to 1992, 2210 inpatients with incident Qwave myocardial infarction aged 25-74 years were included, of whom 468 had diabetes. Primary end point was mortality within 28 days and over 5 years. General linear model procedures were used for age-adjustment, controlling for sex, and testing significance; hazard risk ratios were calculated using multivariable Cox proportional hazards model procedures.

Results. During the 5-year follow-up, 598 subjects died (396 diabetic, 202 non-diabetic). The mortality rate within 28 days was $12.6 \%$ in diabetic patients (women $18.0 \%$, men $9.9 \%$ ) and $7.3 \%$ in non-diabetic patients $(p=0.001)$. Mortality in diabetic patients over 5 years was increased by $64 \%$ (95\% confidence interval 1.39-1.95) compared with non-diabetic patients. This was considerably reduced $(p<0.001)$ in patients treated with thrombolytic drugs (risk ratio: diabetes 0.57 , no diabetes 0.65 ) and with beta blockers (0.62 and 0.64) and antiplatelets (0.76 and 0.74) at hospital discharge. Mortality of diabetic patients treated with these drugs was reduced to that of nondiabetic patients without such treatment (risk ratio 1.01 to $1.27 ; p>0.1)$.

Conclusion/interpretation. Diabetic patients after myocardial infarction are at particularly high risk of dying, but benefit clearly from treatment with thrombolytics, beta blockers and antiplatelets. This study does not, however, allow any inferences to be drawn for treatment with angiotensin converting enzyme inhibitors or the impact of left ventricular function. [Diabetologia (2000) 43: 218-226]

Keywords Diabetes mellitus, acute myocardial infarction, 28-day mortality, long-term survival, population-based register, secondary prevention.
Received: 22 March 1999 and in revised form: 22 July 1999 Corresponding author: Dr. H.Löwel, GSF-Research Center for Environmental and Health Institute of Epidemiology, 85764 Neuherberg bei München, Ingolstädter Landstr. 1, Germany

List of abbrevations: ACE, Angiotensin converting enzyme; AST, aspartate aminotransferase; CPK, creatine phosphokinase; ICD, international classification of diseases; $\mathrm{LDH}$, lactate dehydrogenase; MI, myocardial infarction; MONICA, monitoring trends and determinants in cardiovascular disease; RR, hazard risk ratios; SCD, sudden cardiac deaths; WHO, World Health Organization.
Large cohort studies [1-4] and two European MONI$\mathrm{CA}$ (monitoring of trends and determinants in cardiovascular disease) centres $[5,6]$ have published a threefold (men) to sixfold (women) increased incidence of myocardial infarction (MI) in subjects with diabetes mellitus. It is also well established that even newly diagnosed diabetic subjects have an increased atherogenic cardiovascular risk profile such as increased concentrations of total and LDL cholesterol, of triglycerides, glucose, insulin, raised blood pressure, and lower concentrations of HDL cholesterol [7-10]. Recently, results of a population-based cohort 
study from Finland with a 7-year follow-up have suggested that diabetic patients without previous MI (incidence $20 \%$ ) have as high a risk for MI as nondiabetic subjects with previous MI (incidence 19\%; [11]). Furthermore, it has often been reported from large hospital-based studies [12-18] and recently from two population-based MONICA registers [19, 20] that diabetic patients have a worse short-term and long-term prognosis after acute MI compared with non-diabetic patients.

Subgroup analyses from randomized clinical trials have suggested that the modern treatment strategies (thrombolytic agents, beta blockers, antiplatelets, angiotensin converting enzyme (ACE) inhibitors) were not able to reduce the differences in survival after MI between diabetic and non-diabetic patients [21-24]. From the population-based MONICA Augsburg register 1985/1990 a statistically significant increase in 5-year survival after incident Q-wave MI was reported for non-diabetic patients treated with thrombolytic drugs, beta blockers and antiplatelets but no effect for calcium antagonists [25]. There is no population-based data on treatment and longterm survival in diabetic patients who have had a myocardial infarction.

This paper focuses on the impact of diabetes on mortality within 28 days and over 5 years of followup in relation to clinical characteristics and cardiovascular drug treatment. The subjects were inpatients with incident Q-wave MI from the MONICA Augsburg MI Register for the years 1985 to 1992.

\section{Subjects and methods}

The population-based Augsburg MI Register was part of the international World Health Organization (WHO) MONICA Project [26], which has focused on premature MI with traditional cardiovascular risk factors. All the inhabitants of Augsburg (study population 1985: 156000 men, 171000 women; 1992: 186000 men, 191000 women; aged 25 to 74 years) who had an acute non-fatal or fatal MI including sudden coronary death (SCD) were registered according to the WHO MONICA protocol [27]. Methods of case finding and data quality control have been described elsewhere [28]. Briefly, diagnostic criteria for MI were chest pain lasting 20 min or more (not relieved by rest or nitrates), electrocardiographic changes suggestive of an evolving MI according to Minnesota codes including ST elevations [29] and a subsequent increase in the concentration of at least one of three cardiac enzymes [creatinine phosphokinase (CPK), aspartate aminotransferase (AST) and lactate dehydrogenase (LDH)] to more than twice the upper limit of normal. Data on medical history including diabetes mellitus were gathered in a standardized interview by trained nurses after discharge from coronary care units and completed or validated or both by chart review; $70 \%$ of the patients admitted to 17 hospitals of the study region were interviewed at a mean time of 12.4 days after onset of acute symptoms. Laboratory data, vital signs, clinical complications and medication during their stay in hospital as well as at discharge were abstracted from the medical records. Information on drug compliance during long-term follow-up was not available. Data from questionnaires completed by the patients themselves 1 year after the event were used to determine a low degree of switching.

A total of 5502 patients without a known history of previous MI were registered between 1985 and 1992. To obtain a homogenous cohort, only inpatients surviving the first 24 hours $(n=2232)$ with incident $\mathrm{Q}$-wave MI were included in our analysis. Of the 3270 patients who died within $24 \mathrm{~h}$ (SCD) before $(n=2200)$ or after admission to hospital $(n=1070)$ were excluded because of lack of sufficient information on ECG and other diagnostic criteria. Of them, $824(25 \%)$ had a known history of diabetes and for 655 deceased (12\%) no information on history of diabetes could be obtained. Of those who survived $24 \mathrm{~h}$, 22 with missing data on previously diagnosed diabetes were excluded from the analyses. At discharge, 45 patients $(11 \%)$ received insulin only, 32 patients $(8 \%)$ received insulin in combination with other antidiabetic drugs, 176 patients $(44 \%)$ received mostly sulphonylurea drugs and for 150 patients $(37 \%)$ no antidiabetic medication was recommended by hospital physicians; it can therefore be assumed that the majority of these patients had Type II (non-insulin-dependent) diabetes mellitus [30].

Information about the vital status of each registered patient was obtained by address search and contacting the regional registration offices; there were 66 patients with a follow-up time less than 5 years (mean observation time 4.2 years). The cause of death was taken from the original death certificates and validated by a questionnaire mailed to the coroner or the last treating physician or both. Four main groups of causes of death were summarized: coronary heart disease [international classification of diseases (ICD) 410-414], other cardiovascular diseases (ICD 390-409, 415-459), cancer (ICD 140-208) and the remaining causes.

For medical care consequences, two criteria for survival after MI were defined: a survival of 28 days for inpatients (acute phase of MI, WHO phase I) and of up to 5 years for those who survived 28 days (secondary prevention, WHO phase II).

Statistical analysis. All analyses were done separately for diabetic and non-diabetic patients by sex using the SAS statistical package (Version 6.12, SAS Institute Inc., Cary N. C., USA). All characteristics of diabetic and non-diabetic patients including those who died within 28 days were age-adjusted by the general linear 
Table 1. Number of inpatients with an incident Q-wave myocardial infarction (MI; $n=2210)$, number of deaths within 28 days $(n=186)$ and within 5 years after 28-day survival $(n=412)$. Augsburg Myocardial Infarction Register 1985-1992, 5-year mortality follow-up 1997

\begin{tabular}{|c|c|c|c|}
\hline \multirow{2}{*}{$\begin{array}{l}\text { Age groups } \\
\text { (years) }\end{array}$} & \multirow{2}{*}{$\begin{array}{l}\text { Number of } \\
\text { MI patients } \\
n=100 \%\end{array}$} & \multicolumn{2}{|c|}{ Number of deaths } \\
\hline & & $\begin{array}{l}\leq 28 \text { days } \\
n(\%)\end{array}$ & $\begin{array}{l}>28 \text { days to } 5 \text { years } \\
n(\%)\end{array}$ \\
\hline All men & 1645 & $123(7.5)$ & $282(17.1)$ \\
\hline $\begin{array}{l}\text { Diabetic women } \\
25-54 \\
55-64 \\
65-74\end{array}$ & $\begin{array}{r}181 \\
10 \\
40 \\
131\end{array}$ & $\begin{array}{c}34(18.8) \\
- \\
6(15.0) \\
28(21.4)\end{array}$ & $\begin{array}{r}58(32.0) \\
4(40.0) \\
14(35.0) \\
40(30.5)\end{array}$ \\
\hline All women & 565 & $63(11.2)$ & $130(23.0)$ \\
\hline All men and women & 2210 & $186(8.4)$ & $412(18.6)$ \\
\hline
\end{tabular}

model procedure (GLM); a $p$ value less than 0.05 was considered significant. Hazard risk ratios (RR) with $95 \%$ confidence intervals (CI) describing the risk of death in diabetic compared with non-diabetic 28-day survivors were calculated using the multivariable Cox proportional hazards model (PHREG procedure in SAS [31]); statistical significance was given, if " 1 " was not included. Actuarial survival curves were produced by the SAS-LIFETEST procedure [32].

\section{Results}

Between 1985 and 1992, a total of 2210 patients aged 25-74 years whose history or lack of history of diabetes was known (1645 men, 565 women) were admitted to hospital with an incident Q-wave MI. Table 1 shows the number of patients by sex, age groups, history of diabetes and the number of deaths within 28 days ( 123 men, 63 women) and during the following 5 years (282 men, 130 women). At baseline, 468 patients $(21 \%$; men $17 \%$, women $32 \%$ ) were diabetic and 65 (13.9\%; men $10.8 \%$ and women $18.8 \%$ ) of them died within 28 days and another 137 (29.3\%; men 27.5 and women 32.0 ) died during the following 5 years. The corresponding crude case fatalities for the 1742 non-diabetic patients were $6.9 \%$ (121 deaths) and $15.8 \%$ (275 deaths). Main causes of death (not shown in Table 1 were coronary heart disease among diabetic (79\%) and non-diabetic $(75 \%)$ deaths; causes of death of the remainder were other cardiovascular disease (diabetes $7 \%$, no dia- betes $8 \%$ ) and cancer (diabetes $8 \%$, no diabetes $8 \%$ ) and other causes (diabetes $6 \%$, no diabetes $9 \%$ ). Table 2 compares the age-adjusted baseline characteristics in diabetic ( 287 men, 181 women) and non-diabetic patients (1358 men, 384 women). Compared with non-diabetic patients, those with diabetes in general were older (men: 61 vs 58 years and women 67 vs 64 years, respectively), were more often female ( $35 \%$ vs $23 \%$ ) more frequently had a history of hypertension (men 56 vs $44 \%$, women 73 vs $60 \%$ ) and were less frequently cigarette smokers (men 39 vs $50 \%$,women 22 vs $30 \%$; all differences $p<0.001$ ). Compared with non-diabetic patients and diabetic men, diabetic women were characterized further by the longest prehospital delay, the lowest percentage of thrombolysis ( $13 \%$ vs 27 to $32 \% ; p=0.0001)$, the lowest rates of coronary angiography $(27 \%$ vs 42 to $55 \% ; p=0.0003)$ and exercise stress testing (23\% vs 37 to $45 \% ; p=0.001)$. In both sexes, coronary angioplasty and coronary bypass grafting played a minor part at the time of the study in this population. There were significant differences in drug prescriptions: during the acute phase, diabetic patients received beta blockers less often (men 54 vs $65 \%$, women 46 vs $61 \% ; p<0.001)$ and antiarrhythmic drugs (men $37 \%$ vs $44 \%$, women 30 vs $42 \%$; $p<0.05$ ) compared with non-diabetic patients. Calcium-channel blockers and diuretics were more often prescribed in diabetic compared with non-diabetic men and women, whereas ACE-inhibitors were prescribed in about $20 \%$ of diabetic patients and non-diabetic women but only in $12 \%$ of non-diabetic men $(p=0.0002)$. 
Table 2. Age-adjusted baseline characteristics of inpatients with incident Q-wave myocardial infarction $(n=2210)$ by history of diabetes mellitus and sex: Augsburg Myocardial Infarction Register 1985-1992

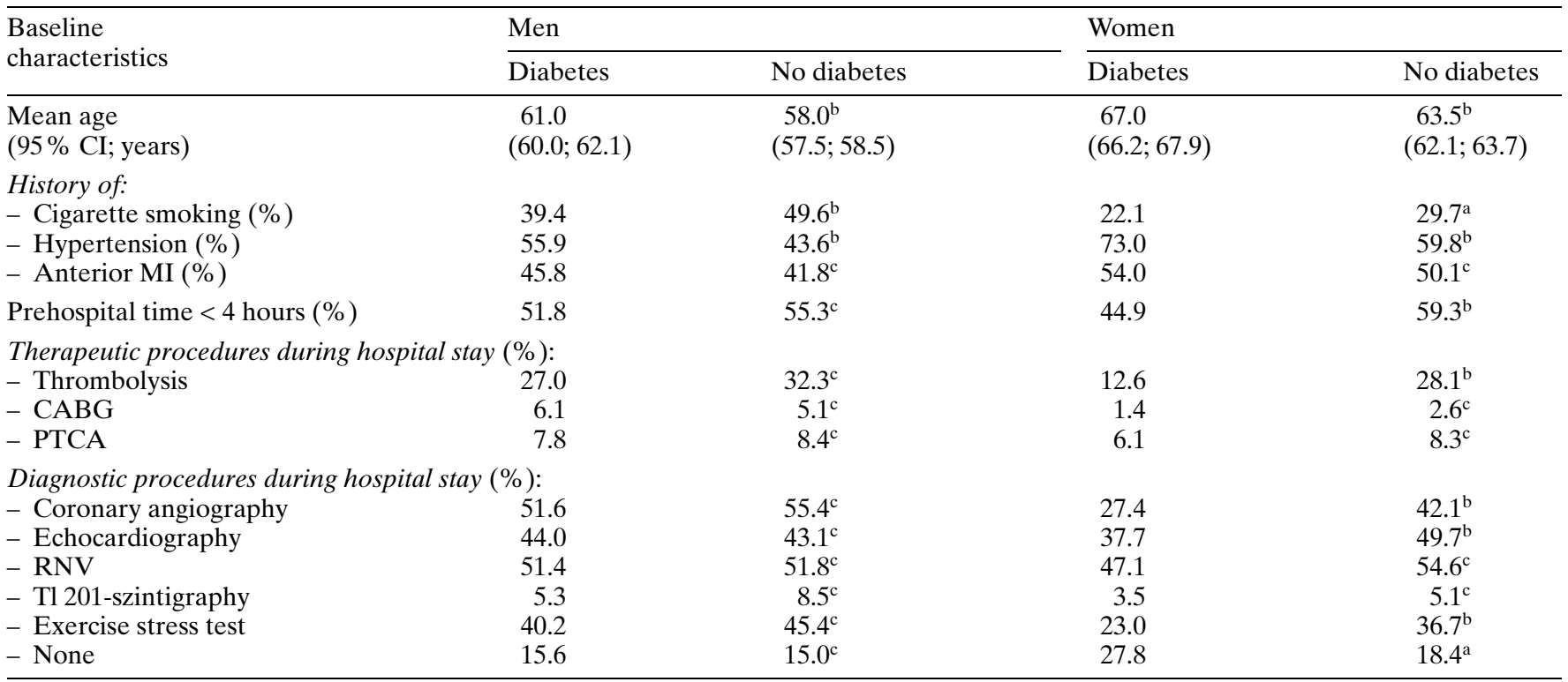

Diabetes vs no diabetes: a $p$ value $<0.01,{ }^{\mathrm{b}} p$ value $<0.05,{ }^{\mathrm{c}} \mathrm{NS}$. RNV, Radionuclide ventriculography; CABG, coronary artery bypass grafting; PTCA, percutane transluminal coronary angioplasty

Table 3. Age-adjusted percentages of drug treatment of patients with incident Q-wave myocardial infarction during their hospital stay $(n=2210)$ and at discharge from hospital $(n=2024)$ by history of diabetes and sex: Augsburg Myocardial Infarction Register 1985-1992

\begin{tabular}{|c|c|c|c|c|}
\hline \multirow[t]{2}{*}{ Medication } & \multicolumn{2}{|c|}{ During hospital stay } & \multicolumn{2}{|c|}{ At discharge } \\
\hline & Diabetes & No diabetes & Diabetes & No diabetes \\
\hline Men & $n=287$ & $n=1358$ & $n=256$ & $n=1266$ \\
\hline Antiplatelet drugs & 77.4 & $78.7^{\mathrm{c}}$ & 68.8 & $70.7^{\mathrm{c}}$ \\
\hline Ca-channel blockers & 76.4 & $71.4^{\mathrm{c}}$ & 52.9 & $50.4^{\mathrm{c}}$ \\
\hline Diuretics & 67.2 & $62.9^{c}$ & 43.7 & $31.8^{\mathrm{a}}$ \\
\hline Beta blockers & 54.3 & $65.3^{\mathrm{a}}$ & 41.2 & $55.4^{\mathrm{a}}$ \\
\hline Antiarrhythmic drugs & 37.0 & $44.4^{\mathrm{b}}$ & 9.6 & $7.2^{\mathrm{c}}$ \\
\hline Lipid lowering drugs & 4.6 & $3.6^{\mathrm{c}}$ & 12.3 & $10.5^{\mathrm{c}}$ \\
\hline Women & $n=181$ & $n=384$ & $n=147$ & $n=355$ \\
\hline Nitrates & 95.3 & $96.2^{\mathrm{c}}$ & 79.8 & $81.2^{\mathrm{c}}$ \\
\hline Antiplatelet drugs & 69.4 & $78.6^{\mathrm{c}}$ & 67.4 & $68.6^{c}$ \\
\hline Ca-channel blockers & 82.5 & $73.3^{\mathrm{b}}$ & 65.1 & $49.1^{\mathrm{a}}$ \\
\hline Antiarrhythmic drugs & 30.4 & $42.4^{\mathrm{a}}$ & 4.3 & $5.4^{\mathrm{c}}$ \\
\hline Lipid lowering drugs & 4.8 & $6.1^{\mathrm{c}}$ & 16.0 & $15.7^{\mathrm{c}}$ \\
\hline
\end{tabular}

Diabetes vs no diabetes: ${ }^{\mathrm{a}} p<0.01,{ }^{\mathrm{b}} p<0.05,{ }^{\mathrm{c}} \mathrm{NS}$

No treatment differences were observed for nitrates, antiplatelet drugs, anticoagulants and lipid lowering drugs. At discharge, diabetic men and women were less likely to receive a beta blocker than non-diabetic men $(p<0.05)$. Diabetic women showed the highest prescription rate of Calcium-channel blockers $(65 \%$ vs 49 to $53 \% ; p=0.001)$ and non-diabetic men were treated less often with ACE-inhibitors compared with the other three patient groups ( $9 \%$ vs 14 to $15 \%, p=0.004)$.

Table 4 summarizes selected patient characteristics of potential relevance for long-term survival by history of diabetes and sex. Mean peaks of enzyme values were significantly lower among diabetic com- 
Table 4. Age-adjusted biochemical and clinical characteristics in 25 to 74-year-old inpatients with incident Q-wave myocardial infarction $(n=2210)$ by sex and history of diabetes: Augsburg Myocardial Infarction Register 1985-1992

\begin{tabular}{|c|c|c|c|c|}
\hline \multirow{2}{*}{$\begin{array}{l}\text { Clinical } \\
\text { characteristics }\end{array}$} & \multicolumn{2}{|l|}{ Men } & \multicolumn{2}{|l|}{ Women } \\
\hline & Diabetes & No diabetes & Diabetes & No diabetes \\
\hline $\begin{array}{l}\text { Peak CPK mean } \\
(\mu / 1,95 \% \mathrm{CI})\end{array}$ & $\begin{array}{l}786 \\
(668 ; 904)\end{array}$ & $\begin{array}{l}831 \\
(790 ; 873)\end{array}$ & $\begin{array}{l}590 \\
(519 ; 660)\end{array}$ & $\begin{array}{l}818 \\
(732 ; 904)\end{array}$ \\
\hline $\begin{array}{l}\text { Peak CK-MB mean } \\
(\mu / 1,95 \% \text { CI })\end{array}$ & $\begin{array}{c}61 \\
(55 ; 67)\end{array}$ & $\begin{array}{c}75 \\
(72 ; 78)\end{array}$ & $\begin{array}{c}57 \\
(51 ; 64)\end{array}$ & $\begin{array}{c}86 \\
(78 ; 93)\end{array}$ \\
\hline $\begin{array}{l}\text { Systolic BP }<100 \mathrm{~mm} \mathrm{Hg} \\
\text { On admission } \\
\text { At discharge }\end{array}$ & $\begin{array}{r}6.5 \\
15.3\end{array}$ & $\begin{array}{r}8.5^{\mathrm{c}} \\
20.3^{\mathrm{c}}\end{array}$ & $\begin{array}{l}8.1 \\
8.0\end{array}$ & $\begin{array}{r}8.9^{\mathrm{c}} \\
17.8^{\mathrm{b}}\end{array}$ \\
\hline $\begin{array}{l}\text { Heart rate }>100 / \min (\%) \\
\text { On admission } \\
\text { At discharge }\end{array}$ & $\begin{array}{r}27.1 \\
5.9\end{array}$ & $\begin{array}{r}17.6^{\mathrm{b}} \\
1.4^{\mathrm{b}}\end{array}$ & $\begin{array}{r}38.9 \\
5.4\end{array}$ & $\begin{array}{r}25.3^{\mathrm{b}} \\
2.4^{\mathrm{c}}\end{array}$ \\
\hline $\begin{array}{l}\text { During hospital stay: } \\
\text { Recurrent MI (\%) } \\
\text { Cardiogenic shock (\%) } \\
\text { Pulmonary oedema (\%) }\end{array}$ & $\begin{array}{r}5.6 \\
10.1 \\
6.9\end{array}$ & $\begin{array}{l}6.6^{\mathrm{c}} \\
5.9^{\mathrm{a}} \\
2.8^{\mathrm{b}}\end{array}$ & $\begin{array}{r}8.0 \\
16.0 \\
4.8\end{array}$ & $\begin{array}{l}6.7 \\
9.0^{\mathrm{a}} \\
3.5^{\mathrm{c}}\end{array}$ \\
\hline
\end{tabular}

Diabetes vs no diabetes: ${ }^{\mathrm{a}} p$ value $>=0.05,{ }^{\mathrm{b}} p$ value $<=0.01,{ }^{\mathrm{c}} \mathrm{NS}$

pared with non-diabetic patients. Cardiogenic shock and pulmonary oedema were higher in diabetic than non-diabetic patients whereas no differences in prehospital cardiac arrest were observed between the four patient groups. After admission to hospital cardiac arrest $(21 \%$ vs $14 \% ; p=0.04)$ and death within 28 days $(18 \%$ vs $7-10 \% ; p=0.001)$ were increased in diabetic women compared with diabetic men and the non-diabetic patients.

Figure 1 presents the observed survival curves for the 5-year follow-up period separately for diabetic and non-diabetic patients adjusted for age, sex and medication; $71 \%$ of the diabetic and $83 \%$ of the non-diabetic patients were still alive 5 years after their incident Q-wave MI (RR 1.64 95\% CI 1.39-1.95; Table 5). The impact of diabetes was highest in the age group 25-54 years (RR 2.29-2.45), decreased with increasing age (RR 65-74 years: RR 1.60-1.78) and varied only little after controlling for confounders. No significant differences were found in long-term survival between male and female diabetic and non-diabetic patients who survived more than 28 days.

Table 6 presents 5-year mortality risk ratios calculated by multivariable Cox proportional hazards model for diabetic and non-diabetic patients separately by age, sex, thrombolysis and medication at discharge. Patients treated with thrombolytic drugs (diabetes RR 0.58; no diabetes RR 0.65), beta blockers (diabetes RR 0.62; no diabetes 0.64) and antiplatelets (diabetes RR 0.76; no diabetes 0.74) showed significant reductions in mortality during the 5-year follow-up after adjustment for potential confounders. Those diabetic patients who received thrombolytic therapy and were prescribed beta blockers or antiplatelets at discharge showed no differences in mortality rate during the 5-year followup compared with non-diabetic patients after controlling for confounders (Table 7). In contrast, treatment with Calcium-channel blockers had no influence on the excess diabetes-related mortality. Treatment with ACE-inhibitors of the subgroup of patients with chronic heart failure at the time of the study was only included in the statistical models as a confounder variable.

\section{Discussion}

These data from a southern German population show an increase in mortality within 28 days of $81 \%$ and within 5 years of follow-up of $64 \%$ in patients with compared with those without diabetes and thus confirm results of previous studies [13-22, 33]. Although increase in mortality in diabetic women within 28 days was clearly related to a more unfavourable treatment profile, no sex differences in long-term mortality were observed. Coronary heart disease was the main cause of death in $79 \%$ of all diabetic and $75 \%$ of all non-diabetic patients after incident Q-wave MI; similar data have been reported from the Minnesota Heart Survey [34] and recently from FINMONICA [22]. The latter study has published similar data for death within 28 days and mortality rates within 1 year for 28-day survivors and the MONICA register in NewSouth Wales [19] also found the highest rates of death within 28 days were in diabetic women. 
Table 5. The 5-year mortality risk ratios with $95 \%$ CI for diabetic patients with a non-fatal incident Q-wave myocardial infarction $(n=403)$ relative to non-diabetic patients $(n=1621)$ adjusted for age, sex, thrombolytic treatment after hospital stay, and drug treatment at discharge using the multivariate Cox proportional hazards model: Augsburg Myocardial Infarction Register 1985-1992, mortality follow-up 1997

\begin{tabular}{llll}
\hline $\begin{array}{l}\text { Age groups } \\
\text { (years) }\end{array}$ & Controlling for & \\
\cline { 2 - 4 } & Sex & $\begin{array}{l}\text { Sex, } \\
\text { hypertension, } \\
\text { anterior MI } \\
\text { smoking }\end{array}$ & $\begin{array}{l}\text { Sex, thrombolysis; } \\
\text { medication at discharge } \\
\text { (antiplatelets, beta blockers, } \\
\text { Ca-channel blockers, } \\
\text { ACE-inhibitors) }\end{array}$ \\
\hline $25-54$ & & $2.31(1.45 ; 3.68)$ & $2.29(1.44 ; 3.64)$ \\
$55-64$ & $2.45(1.56 ; 3.85)$ & $1.77(1.31 ; 2.40)$ & $1.57(1.16 ; 2.11)$ \\
$65-74$ & $1.81(1.35 ; 2.42)$ & $1.78(1.39 ; 2.28)$ & $1.60(1.26 ; 2.03)$ \\
All (adjusted for age) & $1.76(1.40 ; 2.20)$ & $1.85(1.55 ; 2.22)$ & $1.64(1.39 ; 1.95)$ \\
\hline
\end{tabular}

Table 6. Relative risk of 5-year mortality with $95 \%$ CI of diabetic $(n=403)$ and non-diabetic patients $(n=1621)$ with a 28 day survived incident Q-wave myocardial infarction by treatment with thrombolytic drugs after hospital stay and discharge treatment with beta blockers, antiplatelets, antidiabetic drugs vs no such treatment, adjusted for age, sex, and the above mentioned medications, calculated by Cox proportional hazards model: Augsburg Myocardial Infarction Register 1985-1992, mortality follow-up 1997

\begin{tabular}{lll}
\hline & $\begin{array}{l}\text { Diabetes } \\
\text { RR }(95 \% \mathrm{CI})\end{array}$ & $\begin{array}{l}\text { No diabetes } \\
\mathrm{RR}(95 \% \mathrm{CI})\end{array}$ \\
\hline Age (years) & & \\
25-54 & 1.00 & 1.00 \\
$55-64$ & $1.42(0.88-2.30)$ & $2.07(1.57-2.72)$ \\
$65-74$ & $1.70(1.06-2.73)$ & $2.65(2.01-3.49)$ \\
Thrombolytic drugs & $0.58(0.37-0.90)$ & $0.65(0.51-0.81)$ \\
Treatment at discharge & & \\
Beta blockers & $0.62(0.45-0.85)$ & $0.64(0.52-0.78)$ \\
Antiplatelets & $0.76(0.57-1.01)$ & $0.74(0.61-0.90)$ \\
Ca-channel blockers & $0.95(0.72-1.27)$ & $1.12(0.93-1.36)$ \\
ACE-inhibitors & $1.15(0.79-1.66)$ & $1.52(1.15-2.01)$ \\
Sulphonylurea drugs & $0.95(0.72-1.26)$ & - \\
Insulin & $1.63(1.18-2.25)$ & - \\
\hline
\end{tabular}

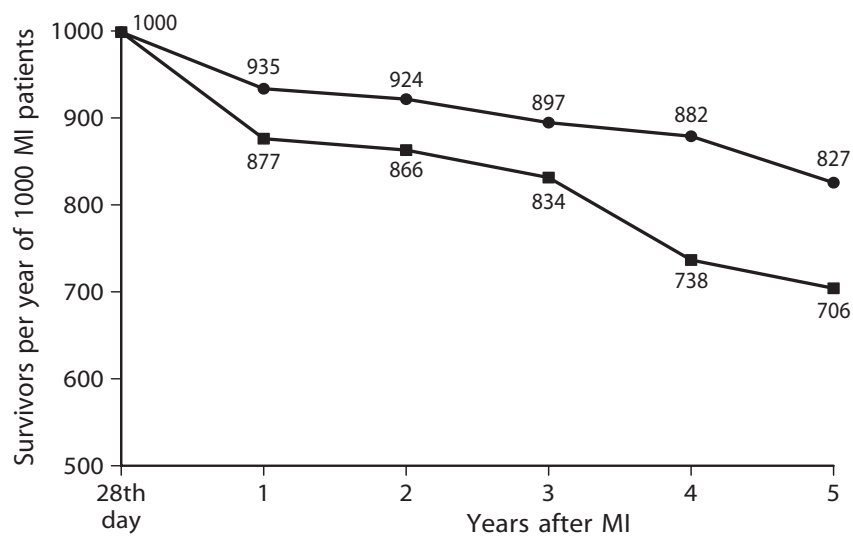

Fig. 1. Observed 5-year survival curves in 28-day survivors after incident Q-wave myocardial infarction by history of diabetes adjusted for age, sex and cardiovascular drug medication. MONICA Augsburg myocardial infarction register 1985-1992, mortality follow-up 1997 - Non-diabetic subjects - - Diabetic subjects
The GUSTO-I-Trial [24], tested the effect of various thrombolytic drugs in acute MI (34888 nondiabetic patients and 4301 Type II diabetic patients; first and recurrent MI with ST elevations) and found a mortality rate within 1 year of those who survived 30 days of $14.5 \pm 0.5 \%$ in diabetic and $8.9 \pm 0.2 \%$ $(p=0.0001)$ in non-diabetic patients. This is nearly identical to that in the population-based Augsburg cohort (Fig. 1) despite the lower percentage of thrombolysis in Augsburg (diabetes $22 \%$, non-diabetes $31 \%$; GUSTO-I $100 \%$ ).

In the Augsburg study, no data could be obtained on results of invasive diagnostic procedures. Based on coronary angiography, the GUSTO-I-Trial reported a more diffuse coronary heart disease in diabetic patients $(32 \%$ with two-vessel and $31 \%$ with threevessel disease; no diabetes $28 \%$ and $21 \%$, respectively). Data from the Corpus Christi Heart Project [35] have suggested that the increased long-term mortality in diabetic patients was largely independent of the severity of MI and thus might reflect the more rapid progression of coronary heart disease and the more frequent occurrence of cardiac failure in diabetic patients. In this study, the peak of cardiac enzyme values for $\mathrm{CPK}$ and creatinine phosphokinase - M (muscle) B (brain) were significantly lower in diabetic than in non-diabetic patients - which was also reported for peak creatinine phosphokinase from the GUSTO-I trial and from FINMONICA [20] - and this also argues against a more severe presentation of the MI in diabetic patients as the reason for their improved prognosis.

As an important result of our population-based observational study over 5 years of a real life situation a remarkable reduction was observed in the mortality rate for diabetic and non-diabetic patients treated with thrombolytic drugs (diabetes $-42 \%$, no diabetes $-35 \%)$, beta blockers ( $-38 \%$ respectively $-36 \%)$, and antiplatelets $(-24 \%$ respectively $-26 \%)$. Effects of thrombolysis and treatment with beta blockers were larger than expected on the basis of randomized clinical trial results $[21,22,24,33,36]$. The effect of an- 
Table 7. Relative risk ratios with $95 \%$ CI of diabetic patients with thrombolysis, discharge medication with beta blockers, antiplatelets or Ca-channel blockers compared with non-diabetic patients without such drug treatment controlled for age, sex, the above mentioned drugs, and ACE-inhibitors a at discharge: Augsburg Myocardial Infarction Register 1985-1992, mortality follow-up 1997

\begin{tabular}{|c|c|c|c|c|c|}
\hline & \multicolumn{2}{|c|}{$\begin{array}{l}\text { Treated } \\
\text { diabetic patients }\end{array}$} & \multicolumn{2}{|c|}{$\begin{array}{l}\text { Non-treated } \\
\text { non-diabetic patients }\end{array}$} & \multirow[t]{2}{*}{ RR $(95 \%$ CI $)$} \\
\hline & $\begin{array}{l}\text { Crude \% of } \\
\text { deaths }(n)\end{array}$ & $\begin{array}{l}\text { Person years } \\
\text { (n) }\end{array}$ & $\begin{array}{l}\text { Crude \% of } \\
\text { deaths }(n)\end{array}$ & $\begin{array}{l}\text { Person years } \\
(n)\end{array}$ & \\
\hline Thrombolytic therapy & $4.9(18)$ & $367(86)$ & $4.3(208)$ & $4818(1085)$ & $1.01(0.67 ; 1.53)$ \\
\hline Beta blockers & $5.2(34)$ & $651(148)$ & $5.2(166)$ & $3202(732)$ & $1.07(0.79 ; 1.44)$ \\
\hline Antiplatelets & $7.3(84)$ & $1143(272)$ & $4.5(94)$ & $2085(477)$ & $1.22(0.96 ; 1.55)$ \\
\hline Ca-channel blockers & $8.3(79)$ & $955(233)$ & $3.3(120)$ & $3676(805)$ & $1.78(1.40 ; 2.27)$ \\
\hline
\end{tabular}

${ }^{a}$ indicating the subgroup of chronic heart failure, ACE-inhibitors (62 diabetic and 161 non-diabetic patients) that had not yet been established for secondary prevention of CHD at the time of the study were used only as confounder

tiplatelets was a $24 \%$ (diabetes) to $26 \%$ (no diabetes) reduction as has been reported by the Anti platelet Trialists for secondary prevention [37]. Data on the benefit of treatment with beta blockers in diabetic patients after an acute MI is scarce [38]. Although the controversial debate on their metabolic side effects potentially outweighing their therapeutic efficacy in diabetics has been settled in the literature [39], there are still some restraints to prescribing beta blockers in diabetic patients in clinical practice (Table 4).

In non-diabetic patients on long-term treatment with ACE-inhibitors (12\%) an increased mortality of $52 \%$ during 5 -year follow-up compared with those without such therapy was observed. Before 1992 the use of ACE-inhibitors after an acute MI, for secondary prevention was, however, not well established. Thus, patients on an ACE-inhibitor, registered before 1992 were only those with severe, symptomatic congestive heart failure carrying an extremely bad prognosis. Therefore, the Augsburg results are not comparable with observations from the GISSI-3 trial [40], where no 6-month survival differences were observed in non-diabetic MI patients treated with an ACE inhibitor compared with the control group and a benefit was suggested for diabetic patients (mortality $12.9 \%$ in the treated vs $16.1 \%$ in the control group; odds ratio $0.7795 \%$ CI 0.62 to 0.95 ).

Similarly, beta blockers might have been mainly prescribed to low risk patients (excluding those with chronic obstructive pulmonary disease, heart failure or impaired left ventricular function; [39]). Due to the limitations of the study design we cannot prove whether the observed low mortality can be attributed to the suggested drug effect or is a consequence of treatment assignment. Only a randomized clinical trial could solve this issue.

A further important observation is that diabetic patients with thrombolysis, beta blocker or antiplatelet therapy showed a clearly improved long-term survival; diabetes-related mortality risks were reduced to the level of non-diabetic patients without such medication (non-significant RR between 1.01 and 1.22; Table 7). For the above mentioned reasons, we were, however, not able to reliably assess the effect of ACE inhibitor use or the impact of impaired left ventricular function on survival. Despite this, our results underscore the importance of optimal treatment in both diabetic and non-diabetic patients in the acute phase and during secondary prevention.

In practice, the importance of rigorously intervening in all patients with diabetes to control glycaemia, lower blood pressure and blood lipids should be emphasized [35, 36, 41-43]. Data from the 4S-study and the CARE-study have clearly shown that long-term treatment with lipid lowering drugs, like simvastatin or pravastatin, provide an effective strategy to improve survival in diabetic and non-diabetic patients who have had a MI and have a normal or moderately high serum cholesterol $[44,45]$.

Despite the observational nature of the Augsburg study and its inherent limitations, diabetes remains an important predictor of short-term and long-term mortality after MI even in the thrombolytic era. Finally, as surveys like EUROASPIRE [46] have shown, the evidence from clinical trials needs to be taken into account in clinical practice. This seems to be even more important in patients with than in those without diabetes [47].

Acknowledgements. We wish to thank the following people for their contribution to the Augsburg MI Register: P.Pitschi, C. Winter and G.Zimmermann (patient interviews and chart abstracting), U. Hazijenko, D. Lukitsch (register organisation); Dr. K. Karl, M.Thierbach, P. Viel (Minnesota ECG coding); Professor J. Gostomzyk, Dr. C. Schomann, Dr. U. Warnke, Dr. R. Deckart and the private physicians of the study area (validation of death certificate diagnoses); Professor H.D. Bolte and the other hospital staff physicians (identification of inpatients); Dr. C.Bannert and Dr. M.Heier (pharmaceutical support); Dr.R. Engelbrecht (implementation of the drug data base Medais); D. Janku, A. Schneider and U. Kaup (data management and evaluation); N. Jacobsen (literature service); I. Trentinaglia (statistical programming); and last but not least, all the MI patients for their willingness to participate. 


\section{References}

1. Kannel W-B, McGee D-I (1979) Diabetes and cardiovascular disease. The Framigham Study. J Am Med Assoc 241: 2035-2038

2. Koskinen P, Manttari M, Manninen J, Heinonen O-P, Frick MHS (1992) Coronary heart disease incidence in NIDDM patients in the Helsinki Heart study. Diabetes Care 15: 820-825

3. Stamler J, Vaccaro O, Neaton J, Wentworth D (1993) Diabetes, other risk factors, and 12-yr. cardiovascular mortality for men screened for the Multiple Risk Factor Intervention Trial. Diabetes Care 16: 434-449

4. Folsom A-R, Szklo M, Stevens J, Liao F, Smith R, Eckfeldt J-H (1997) A prospective study of coronary heart disease in relation to fasting insulin, glucose, and diabetes. Diabetes Care 20: 935-942

5. Löwel H, Stieber J, Koenig W, et al (1999) The diabetesrelated risk of MI in a Southern German population: results of the MONICA Augsburg studies 1985-1994 (in German). Diabetes und Stoffwechsel 8: 11-21

6. Lundberg V, Stegmayr B, Asplund K, Eliasson M, Huhtasaari F (1997) Diabetes as a risk factor for MI: population and gender perspectives. J Intern Med 241: 485-492

7. Pyörälä K, Laakso M, Uusitupa M (1987) Diabetes and atherosclerosis: an epidemiological view. Diabetes Metab Rev 3: 463-524

8. Standl E, Balletshofer B, Dahl B et al (1996) Predictors of 10-year macrovascular and overall mortality in patients with NIDDM: The Munich General Practitioner Project. Diabetologia 39: 1540-1545

9. Hanefeld M, Fischer S, Julius U et al, The DIS group (1996) Risk factors for MI and death in newly detected NIDDM: the Diabetes Intervention Study, 11-year followup. Diabetologia 39: 1577-1583

10. Meigs J-B, Singer D-E, Sullivan L-M et al (1997) Metabolic control and prevalent cardiovascular disease in noninsulin-dependent diabetes mellitus (NIDDM): The NIDDM Patient Outcomes Research Team. Am J Med 102: $38-47$

11. Haffner S-M, Lehto S, Rönnemaa T, Pyörälä K, Laakso M (1998) Mortality from coronary heart disease subjects with type 2 diabetes and in non-diabetic subjects with and without prior MI. N Engl J Med 339: 229-234

12. Bradley R-F, Bryfogie J-W (1956) Survival of diabetic patients after MI. Am J Med 20: 207-216

13. Ulvenstam G, Aberg A, Bergstrand R et al (1995) Longterm prognosis after MI in men with diabetes. Diabetes 34: 787-792

14. Abott R-D, Donahue R-P, Kannel W-B, Wilson P-W-F (1988) The impact of diabetes on survival following MI in men vs women. JAMA 260: 3456-3460

15. Greenland P, Reicher-Reiss H, Goldbourt U, Behar S (1991) In-hospital and 1-year mortality in 1524 women after MI: comparison with 4315 men. Circulation 83: 484-491

16. Karlson W, Herlitz J, Hjalmarson A (1993) Prognosis of acute MI in diabetic and non-diabetic patients. Diabet Med 10: 449-454

17. Abbud Z-A, Shindler D-M, Wilson A-C, Kostis L-B, for the MI Data Acquisition System Study Group (1995) Effect of diabetes mellitus on short- and long-term mortality rates of patients with acute MI: A statewide study. Am Heart J 130: 51-58

18. Behar S, Boyko V, Reicher-Reiss H, Goldbourt U, for the SPRINT Study Group (1997) Ten-year survival after acute MI: Comparison of patients with and without diabetes. Am Heart J 133: 290-296
19. Chun B-Y, Dobson A-J, Heller R-F (1997) The impact of Diabetes on survival among patients with first MI. Diabetes Care 20: 704-708

20. Miettinen H, Lehto S, Solomaa V, et al (1998) Impact of diabetes on mortality after the first MI. Diabetes Care 21: 69-75

21. Zuanetti G, Latini R, Maggioni A-P, Santoro L, Franzosi M-G on behalf of GISSI-2-Investigators (1993) Influence of diabetes on mortality in acute MI: data from the GISSI2 study. J Am Coll Cardiol 22: 1788-1794

22. Barbash G-I, White H-D, Modan M, Ven de Werf F, for the Investigators of the International Tissue Plasminogen Activator/Streptokinase Mortality Trial (1993) Significance of diabetes mellitus in patients with MI receiving thrombolytic therapy. J Am Coll Cardiol 22: 707-713

23. Becker R-C, Terrin M, Ross R et al, and the Thrombolysis in MI Investigators (1994) Comparison of clinical outcomes for women and men after acute MI. Ann Intern Med 120: 638-645

24. Mak K-H, Moliterno D-J, Granger C-B et al, for the GUSTO-I Investigators (1997) Influence of diabetes mellitus on clinical outcome in thrombolytic era of acute MI. J Am Coll Cardiol 30: 171-179

25. Koenig W, Löwel H, Lewis M, Hörmann A (1996) Longterm survival after MI: relationship with thrombolysis and discharge medication. Eur Heart J 17: 1199-1206

26. World Health Organization Principal Investigators (prepared by H Tunstall-Pedoe) (1988): The World Health Organziation MONICA Project (Monitoring of Trends and Determinants in Cardiovascular Disease): A major international collaboration. J Clin Epidemiol 34: 105-114

27. The World Health Organzation (1990) MONICA Manual (Revised Edition) Cardiovascular Disease Unit, World Health Organization, Geneva

28. Löwel H, Lewis M, Hörmann A, Keil U (1991) Case finding, data quality aspects, and comparability of MI registers. Results of a Southern German register study. J Clin Epidemiol 44: 249-260

29. Prineas R-J, Crow R-S, Blackburn H (1992) The Minnesota code manual of electrocardiographic findings: standards and procedures for measurement and classification. John Wright, Boston, Bristol

30. The Expert Committee on the Diagnosis and Classification of Diabetes mellitus (1997) Report of the Expert Committee on the Diagnosis and Classification of Diabetes mellitus. Diabetes Care 20: 1183-1197

31. The PHREG Procedure (1996) In: SAS/STAT software changes and enhancements. Cary (NC): SAS Institute $807-884$

32. The LIFETEST Procedure (1990) In: SAS/STAT User's Guide, version 6, vol.2, 4th ed. Cary (NC): SAS Institute: 1027-1069

33. Avanzini F, Zuanetti G, Latini R et al, on behalf of the Gruppo Italiano di Studio sulla Sopravvivenza nell'Infarto Miocardico (GISSI) Investigators (1997) Use of betablocking agents in secondary prevention after MI: a case for evidence-based medicine? GISSI experience, 1984-1993. Eur Heart J 18: 1447-1456

34. Pankow J-S, McGovern P-G, Sprafka L-M, Jacobs R, Blackburn H (1994) Trends in coded causes of death following definitive MI and the role of competing risks: The Minnesota Heart Survey (MHS). J Clin Epidemiol 47: 1051-1060

35. Orlander P-R, Goff D-C, Morrissey M et al (1994) The relation of diabetes to the severity of acute MI survival in Mexican-Americans and non-Hispanic whites. The Corpus Christi Heart Project. Diabetes 43: 897-902 
36. Hjalmarson A (1997) Effects of betablockade on sudden cardiac death during acute MI and the postinfarction period. Am J Cardiol 80 (9B): 35J-39J

37. American Diabetes Association (1998) Position statement: Aspirin therapy in Diabetes. Diabetes Care 21 [Suppl 1]: $1-3$

38. MacDonald T-M, Butler R, Newton R-W, Morris A-D (1998) Which drugs benefit diabetic patients for secondary prevention of myocardial infarction? DARTS/MEMO Collaboration. Diabet Med 15: 282-289

39. Gottlieb S-S, McCarter R-J, Vogel R-A (1998) Effect of beta-blockade on mortality among high-risk and low-risk patients after myocardial infarction. N Engl J Med 339: 489-497

40. Zuanetti G, Latini R, Maggioni A-P, Franzosi M-G, Santoro L, Tognoni G, for the GISSI-3 Investigators (1997) Effect of the ACE inhibitor lisinopril on mortality in diabetic patients with acute MI. Circulation 96: 4239-4245

41. Harris M-I, Eastman R-C (1998) Is there a glycemic threshold for mortality risk? Diabetes Care 21: 331-333

42. Pyörälä K, De Backer G, Graham I, Poole-Wilson P, Wood D, on behalf of the Task Force (1994) Prevention of coronary heart disease in clinical practice. Recommendations of the Task Force of the European Society of Cardiology, European Atherosclerosis Society and European Society of Hypertension. Eur Heart J 15: 1300-1331

43. Hanefeld M, Schmechel H, Schwanebeck U, Lindner J (1997) Predictors of coronary heart disease and death in NIDDM: The Diabetes Intervention Study experience. Diabetologia 40: S123-S124

44. Pyörälä K, Pedersen T-R, Kjekshus J, Faergeman O, Olsson A, Throgeirsson G, for the Scandinavian Simvastatin Survival Study Group (1997) Lowering cholesterol levels improved the prognosis of diabetic patients with coronary heart disease. Diabetes Care 20: 614-620

45. Sacks F-M, Pfeffer M-A, Moye L-A et al, for the physicians of the CARE study (1996) The effect of pravastatin on coronary events after MI in patients with average cholesterol levels. N Engl J Med 335: 1001-1009

46. EUROASPIRE (1997) A European Society of Cardiology survey of secondary prevention of coronary heart disease: Principal results. Eur Heart J 18: 1569-1582

47. Grundy S-M, Balady G-J, Criqui M-H et al (1997) Guide to primary prevention of cardiovascular diseases. A statement for healthcare professionals from task force in risk reduction. Circulation 95: 2329-2331 